\title{
Analysis of the Most Important Factors that Affect Tensile and Shear Strength of Dual-Phase Steels Using Taguchi Method
}

\begin{abstract}
S.E. CömerT*, F. Yener, S. KIR And H.R. YAZGan
Sakarya University, Engineering Faculty, Department of Industrial Engineering, Sakarya, Turkey

Dual-phase steels are high-strength steels which are heat treated to contain both a ferrite and martensite microstructure to achieve an extra strength. They have high formability, low alloy content, and high strength. In today's competitive environment, the aim of businesses is to produce quality products with a low cost. The quality is taken into consideration substantially in products selection. In this study, the DP 600 series of the dual-phase steel group, which has become widespread in the automotive sector in recent years, is discussed and the most important factors and factor levels affecting the tensile and shear strength of these automotive sheets are analyzed using the Taguchi method. The main reason of using the Taguchi method is to reduce the number of experiments to be performed using orthogonal arrays. So it is expected to achieve less time and labor force and low cost. Firstly, the average and $\mathrm{S} / \mathrm{N}$ ratio for each experiment using the L16 orthogonal array are calculated and found which levels are more appropriate for the factors. Then, analysis of variance is performed in order to determine the factors, which significantly affect the tensile and shear strength of dual-phase 600 type automobile sheets.
\end{abstract}

DOI: 10.12693/APhysPolA.135.684

PACS/topics: dual-phase, tensile and shear strength, Taguchi experimental design

\section{Introduction}

Manufacturers always compete with each other to offer cheaper products beyond the expected quality standards. They make an effort for delivering high quality, cheaper, and more innovative products to customers in short periods. Therefore, this increases the awareness level of quality development. Taguchi has also made significant contributions to the acceptance of the experimental design method in the manufacturing sector by introducing new ideas and demonstrating successful applications, although it has made a significant innovation in terms of the method for experimental design [1]. The Taguchi method is a very useful method for determining the best combination of different parameters at different levels. Taguchi has developed orthogonal arrays to achieve good results with very little experimentation. In cases where it is necessary to conduct a lot of experimental study for all combinations of each level and each parameter, the result can be achieved with a much smaller number of experimental works using the orthogonal array [2]. In this study, the DP 600 series of dual-phase steel group, which has become popular in the automotive sector in recent years, is considered and the most important factor levels affecting the tensile and shear strength of these automotive sheets is determined using the Taguchi method of quality improvement methods.

*corresponding author; e-mail: serape@sakarya.edu.tr

\section{Dual-phase steels}

Dual-phase steels are high strength steels and are heat treated to provide both ferrite and martensite microstructure. The ferrite phase surrounds the martensite islands and the tensile strength is increased by increase of the amount of martensite. Dual-phase steels are fast becoming one of the popular materials of today's automobile industry. The dual-phase steel, called DP 600, is newly developed for the automotive industry and has $600 \mathrm{MPa}$ strength. DP 600 steels are specifically designed to meet the requirements of light weight, high strength, safety, good corrosion resistance, and good sanding characteristics in automobile body [3]. When the number of factors and factor levels increase, the number of experiments will increase to find the tensile and shear strength of DP 600 steels. This is a disadvantage both in terms of time and cost. For this reason, this study aimed to reduce the number of experiments by using the Taguchi method and then found which factor levels are effective.

\section{Taguchi method}

The Taguchi method is an experimental design method that attempts to minimize the variability of the product and process by selecting the most appropriate combination of factor levels that can be controlled against variable and uncontrollable factors. The Taguchi experimental design technique gives better results with less trial to improve quality [4]. Taguchi defines a criterion called signal-to-noise ratio $(\mathrm{S} / \mathrm{N})$, which is used as a performance criterion in experimental design in order to reduce diversity. Taguchi has divided the problem into practice 
according to the target and defined a different signal-tonoise ratio for each. When the signal-to-noise ratios are evaluated, it is necessary to determine the appropriate one among the smaller-the-better, nominal-the-best, and larger-the-better criteria. Whichever of these criteria is used, the high $\mathrm{S} / \mathrm{N}$ ratio indicates best experimental results. Therefore, factor levels with the highest $\mathrm{S} / \mathrm{N}$ ratio will give the best performance. However, it can be seen from the graphs which of the factors have more significant effect on the process by performing the analysis of variance (ANOVA). The Taguchi experimental design technique steps are as follows. First of all, factors and their interactions (using brainstorming, flow diagram, cause and effect diagram, etc. ) are selected. Secondly, factor levels are determined and a suitable orthogonal array are selected. Then, factors and/or interactions between them to the column are assigned and experiments as planned in previous steps are realized. Finally, the results are analyzed [5].

\section{Application}

This study deals with manufacturing the DP 600 series of dual-phase steel which becomes more popular in the automotive industry in recent years. In order to be the preferred company in the market, there is a need to some studies about the tensile and shear strength of these automotive sheets. Therefore, researchers deal with the Taguchi method to determine the most important factor level affecting the tensile and shear strength of automotive sheets. Firstly, factors that affecting the tensile and shear strength of the DP 600 series automobile sheets are determined. These factors are automobile sheet thickness, welding current, welding time, and electrode pressure. Each of these factors has four levels. The factors and factor levels are shown in Table I.

TABLE I

Level of the specified factors for the experiment

\begin{tabular}{c|c|c|c|c|c}
\hline \hline Factor & Levels & & Factor & Levels & \\
\hline automobile & 1 & $1 \mathrm{~mm}$ & & 1 & $5 \mathrm{~min}$ \\
sheet & 2 & $1.2 \mathrm{~mm}$ & welding & 2 & $10 \mathrm{~min}$ \\
thickness & 3 & $1.3 \mathrm{~mm}$ & time & 3 & $15 \mathrm{~min}$ \\
& 4 & $1.5 \mathrm{~mm}$ & & 4 & $20 \mathrm{~min}$ \\
\hline & 1 & $4 \mathrm{kA}$ & & 1 & $4 \mathrm{kN}$ \\
welding & 2 & $5 \mathrm{kA}$ & electrode & 2 & $5 \mathrm{kN}$ \\
current & 3 & $6 \mathrm{kA}$ & pressure & 3 & $6 \mathrm{kN}$ \\
& 4 & $7 \mathrm{kA}$ & & 4 & $7 \mathrm{kN}$
\end{tabular}

$L_{16}$ orthogonal array is generated according to the mentioned factors and factor levels. Sixteen experiments are carried out and these experiments are repeated five times to test the tensile and shear strength of dual-phase steels in management. Experimental results are shown in Table II.

The factors, factor levels, and test results of problem are analyzed using a commercial statistical software. Because of DP 600 series requirement of a high tensile and
Experimental results

TABLE II

\begin{tabular}{c|c|c|c|c|c}
\hline \hline \multirow{2}{*}{$\begin{array}{c}\text { Experiment } \\
\text { No. }\end{array}$} & \multicolumn{5}{|c}{ Experimental results [daN] } \\
\cline { 2 - 6 } & $Y_{1}$ & $Y_{2}$ & $Y_{3}$ & $Y_{4}$ & $Y_{5}$ \\
\hline 1 & 740 & 741 & 738 & 735 & 736 \\
2 & 870 & 869 & 872 & 875 & 871 \\
3 & 980 & 982 & 978 & 979 & 981 \\
4 & 1150 & 1148 & 1152 & 1155 & 1157 \\
5 & 765 & 766 & 767 & 764 & 763 \\
6 & 890 & 892 & 889 & 893 & 887 \\
7 & 1050 & 1052 & 1051 & 1048 & 1046 \\
8 & 1250 & 1253 & 1251 & 1247 & 1248 \\
9 & 820 & 818 & 817 & 817 & 825 \\
10 & 940 & 942 & 943 & 941 & 938 \\
11 & 1020 & 1021 & 1017 & 1022 & 1015 \\
12 & 1200 & 1203 & 1201 & 1198 & 1199 \\
13 & 850 & 848 & 845 & 852 & 853 \\
14 & 960 & 957 & 958 & 962 & 961 \\
15 & 1030 & 1027 & 1028 & 1031 & 1035 \\
16 & 1180 & 1178 & 1185 & 1182 & 1181
\end{tabular}

a shear strength of automotive sheet, the $\mathrm{S} / \mathrm{N}$ ratio is chosen as "larger-the-better" criterion. According to the results of the analysis, fourth level for automobile sheet thickness and welding current, third and fourth level for welding time, and second level for electrode pressure are the most appropriate level. Variance analysis is also conducted after finding which levels are more appropriate for the factors, and it is found which factors have statistically significant effects for the tensile and shear strength of DP 600 automobile sheets. The ANOVA results are shown in Table III.

The results illustrate that automobile sheet thickness, welding current, and welding time are the most important factors. The $F$ test values of these three factors are big and the probability values $(P$ value $)$ are less than 0.05 .

TABLE III

Variance analysis for tensile and shear strength of DP 600 series automobile sheet

\begin{tabular}{l|c|c|c|c|c}
\hline \hline \multicolumn{1}{c|}{ Source } & DF & Adj SS & Adj MS & $F$ value & $P$ value \\
\hline automobile sheet & 3 & 11792 & 3931 & 21.75 & 0.015 \\
thickness & & & & & \\
welding current & 3 & 346942 & 115647 & 639.89 & 0.000 \\
welding time & 3 & 6017 & 2006 & 11.10 & 0.039 \\
electrode pressure & 3 & 2417 & 806 & 4.46 & 0.126 \\
error & 3 & 542 & 181 & & \\
total & 15 & 367711 & & &
\end{tabular}

\section{Conclusion}

In this paper, we employ the Taguchi method to analyze the tensile and shear strength of the DP 600 series dual-phase steel group in automotive sheets. The factors 
that affect the tensile and shear strength of dual-phase 600 type automobile sheets are determined and then levels for each factor are decided. $L_{16}$ orthogonal array is chosen for the Taguchi experimental design based on number of factors and levels. A commercial statistical software is used to analyze the Taguchi experiment results and then ANOVA test is implemented. ANOVA test results indicates that automobile sheet thickness, welding current, and welding time are the most influencing factors for dual-phase 600 type automobile sheets. As a result, the approach can be used for several quality improvement application.

\section{References}

[1] E. Caniylmaz, F. Kutay, J. Fac. Eng. Arch. Gazi Univ. 18, 51 (2003).

[2] M. Şirvanc1, Experimental Design Approach for Quality, Taguchi Approach, University of Wisconsin Business School, USA 1997.

[3] D.T. Llewellyn, D.J. Hillis, Ironmak. Steelmak. 23, 471 (1996).

[4] P.J. Ross, Taguchi Techniques for Quality Engineering, McGraw-Hill, Singapore 1989.

[5] M. Savaşkan, Y. Taptık, M. Ürgen, J. ITU/d Eng. 3, 117 (2004). 